\title{
Materiais Didáticos à Luz da Lei 10.639/03: Por Um Ensinar e Aprender uma Geografia Anti-Racista
}

Cesar Augusto Caldas Santos

Raphael Luiz Silva da Costa

\section{Resumo}

O preconceito racial se faz presente em todas as dimensões das relações humanas, logo, o campo da educação não esta imune a ele. Acreditamos que é no espaço escolar que se dá grande parte da formação humana dos indivíduos. Este espaço que deveria ser isento de estereótipos e segregação é carregado de preconceitos que da forma mais perversa marcam a trajetória escolar - e de vida - dos alunos negros.

A Geografia tem fundamental papel para o reforço destes estereótipos, todavia também possui os conhecimentos e os meios para a luta contra estes. $\mathrm{E}$, a partir de um novo olhar na relação aprender-ensinar Geografia se torna possível caminhar para uma educação anti-racista.

Nossa proposta é discutir como o conceito de raça funciona como principio de organização e hierarquização espacial e como isso esta representado, através das subjetividades de imagens e conteúdos, nos materiais didáticos de Geografia de ensino básico.

Palavras-Chaves: Raça; Livro Didático; Ensino de Geografia.

\section{Abstract}

Racial prejudice is present in all dimensions of human relationships, so the field of education is not immune to it. We believe that is in the school that gives much of human individuals development. This space that should be free of stereotypes and segregation is full of prejudices that of most perverse form mark the school career - the life - of the black students.

Geography plays an essential role in reinforcing these stereotypes, but also has the knowledge and means to combat them. And, from a new perspective on teaching-learning relationship Geography becomes possible to walk for an anti-racism education.

Our proposal is to discuss how the concept of race serves as the organizing principle of hierarchy and space and how it is represented by the subjectivities of images and content in the textbooks of geography education.

Key Words: Race; Textbooks, Teaching of Geography

\section{Raça e (controle) do Espaço}

Embora a ciência tenha refutado a idéia que a ela própria construiu de que biologicamente - e, portanto naturalmente - alguns homens eram superiores aos outros, a permanência dessa premissa no imaginário dos povos deixa evidente a conveniência de tal formulação para a manutenção do sistema-mundo-moderno-colonial. Baseado na existência de diferentes raciais é que o Ocidente construiu - e os países centrais mantêm - as bases da 


\section{REVISTA TAMOIOS}

exploração sobre os continentes conquistados entre os séculos XV e XIX hoje periferias ou semi-periferias.

A suposta inferioridade racial se refletia na desqualificação das manifestações culturais e técnicas ameríndias e africanas. As "limitações cognitivas", que eram associadas às suas aparências externas, impossibilitavam esses grupos humanos de, por si só, desenvolverem padrões de moral e valores justos, e avanços técnicos que fossem capazes de libertálos do "anacronismo" em que se encontravam em relação à civilização européia.

Com base nesta idéia que Ginés de Sepúlveda buscou legitimar, a relação de dominação/exploração que os espanhóis estabeleceram na América. No seu discurso, afirmava que os ameríndios eram "bárbaros, simplórios, iletrados e não instruídos, cruéis, brutos totalmente incapazes de aprender qualquer coisa que não seja a atividade mecânica, cheios de vícios, cruéis (...)." (Wallerstein, 2007, p.33) e que por isso mesmo deveriam aceitar, ainda que não quisessem, o controle espanhol, como forma de corrigir os seus atos e de punição às suas práticas perversas, que ofendiam tanto a lei divina como as leis naturais - a idolatria e o sacrifício humano adornavam o seu discurso. Completava enfocando a necessidade de se pôr um freio a essas práticas, a fim de evitar que mais pessoas inocentes fossem sacrificadas nos seus rituais pagãos (ibid, p.34).

O pensamento de Sepúlveda serviu como base, ajustando-se aos interesses comerciais europeus naquele momento histórico, pois legitimava a ingerência dos espanhóis na estrutura social, política, econômica e religiosa das civilizações americanas. Pois eles acreditavam, os espanhóis, que tinham a missão de punir ou converter os pagãos aos valores cristãos - ainda que os métodos utilizados para tal façanha fossem anticristãos - assim, se autorogaram o papel de "civilizar" os não-europeus.

O que interessava ao colonizador não era o colonizado. Aliás, se fosse, não haveria lógica para o extermínio. A disputa era por espaço. Pois os recursos minerais existentes nos territórios das civilizações ameríndias, há tempos, exerciam uma intensa sedução junto aos espanhóis. O objetivo era o controle desses recursos que somente seria possível, na ocasião, a partir do controle do espaço. Daí a necessidade de se criar justificativas morais para uma ação militar a partir da inferiorização do não-europeu.

Mais de trezentos anos se passaram e a estrutura do discurso que legitimou a ingerência dos ibéricos sobre as civilizações indígenas das Américas atravessou a história. Os conceitos utilizados por Sepúlveda transmutaram-se de acordo com as exigências do contemporâneo, hoje, a cristianização não é justificativa para uma ação militar. $E$ há bem da verdade, a soberania das ex-colônias - atualmente países "livres" - deveria funcionar como uma barreira à intervenção de outros países ou organizações internacionais. Mas não é assim que ocorre...

Explicitamente os conceitos de democracia e direitos humanos têm funcionado como argumentos poderosos para tais intervenções em diversos países, mas principalmente naqueles localizados na África, Ásia e América. Ninguém contesta que ditaduras sanguinárias que permanecem há décadas no poder têm que ser derrubadas, mas a suposta incompetência dos movimentos internos que lutam por sua queda sugere uma "ajuda" estrangeira. O estigma da inferiorização e da necessidade da tutela dos países europeus ainda repousa sobre os povos do "Sul". 


\section{REVISTA TAMOIOS}

O mesmo ocorre quando governos dos países pobres se mostram incapazes de solucionar problemas sociais e econômicos, como pauperização da população, doenças, fome dentre outros. Nesses casos, mais uma vez o auxílio externo parece ser a única saída. Os governos da América de "índios e mestiços" e da África seja ela a "negra" ou "branca", assim como alguns governos de países asiáticos, principalmente os do Oriente Médio, tem em seu portfólio uma série de ações estrangeiras, que intentavam por em ordem a casa alheia. $O$ discurso que tem por base a defesa dos direitos humanos dilui a solidez da soberania dos Estados, abre a porta ao invasor e convence, inclusive os de casa, que o melhor é deixar entrar.

Em suma, a necessidade de inferiorização do outro com base em critérios raciais é um tipo de operação que, não somente permite, mas legitima a invasão e o controle do espaço por elementos estrangeiros. Sendo que a produção da inferiorização somente atinge o êxito por sua condição de forte aliada ao interesses econômicos dos países hegemônicos. A "raça" não opera sozinha!

\section{A Geografia e o Livro Didático}

O livro didático de Geografia é um instrumento que deve ser utilizado de forma a potencializar a prática do professor, esta deve estar ancorada a um fim específico, em conformidade àquilo que se espera da disciplina.

Os objetivos da Geografia Escolar variaram no decorrer da história. No final do século XIX, quando foi introduzida no Brasil, tinha ela a função de "contribuir para a formação dos cidadãos a partir da difusão da ideologia do nacionalismo patriótico" (Cavalcanti, 1988, p.18), pois que a conjuntura sóciopolítica do Brasil estava marcada, dentre tantas outras convulsões do final daquele século, pela proclamação da República e, conseqüentemente, pela necessidade de se "produzir" uma identidade nacional.

Vimos em Yves Lacoste a denúncia da ineficiência dessa Geografia pautada na descrição e memorização. Sua crítica tinha por base justamente o fato da Geografia difundida nos círculos escolares se pautar num compêndio de informações desconexas da prática social, por isso mesmo, alienante. É importante conhecer o espaço, mas este conhecimento deve ser apropriado enquanto condição primordial para se agir sobre o espaço (Santos, 2008, p.29). A afirmativa vislumbra

As possibilidades da Geografia e da prática de ensino de cumprirem papéis politicamente voltados aos interesses das classes populares. Nessa perspectiva, os estudiosos alertam para a necessidade de se considerar o saber e a realidade do aluno como referência para o estudo do espaço geográfico (Cavalcanti, 1988, p.20).

Santos completa, quando aponta que

o sentido do aprender e ensinar a Geografia é se posicionar no mundo. Quando falamos isso, estamos indicando, na verdade uma dupla acepção do que chamamos "se posicionar no mundo": (i) conhecer sua posição no mundo, e para isso o indivíduo precisa conhecer o mundo; (ii) tomar posição neste mundo, que significa se colocar politicamente no processo de construção e reconstrução deste mundo. Se posicionar no mundo é, portanto, conhecer a sua posição no mundo e tomar posição neste mundo, agir. Saber Geografia é saber onde você está, conhecer o mundo, mais isto serve fundamentalmente para você agir sobre este mundo no processo de 
reconstrução da sociedade: se apresentar para participar (2007, p.27).

Conhecer o mundo é um dos pilares sobre o qual a ação se sustenta. Nesta perspectiva a Geografia Escolar se configura enquanto conhecimento capaz de promover a emancipação de grupos sociais que permanecem sob histórico de opressão.

O livro didático de Geografia então, como material de apoio, tem como uma de suas funções apresentar o mundo. O que vai configurar problema é a forma como este material irá apresentá-lo; a epistemologia, a base de construção do seu discurso, irá definir uma "representação de mundo", um "tipo específico de mundo", não o mundo real.

\section{Analisando os livros didáticos de Geografia: a produção da inferiorização do outro e a legitimação da ingerência.}

Interessa-nos, nas linhas abaixo, evidenciar algumas das estratégias presentes nos livros didáticos de Geografia de segundo segmento do ensino fundamental que operam na manutenção da ordem do atual sistema-mundo moderno/colonial capitalista - reproduzindo hierarquias e preconceitos - como a desqualificação dos territórios (países ou continentes) ocupados por povos não-europeus; assim como as maneiras que utilizam para reforçar o discurso de inferioridade dos grupos humanos que ocupam estes mesmos territórios.

Para isso nos valeremos de três chaves analíticas que ao nosso ver são fundamentais para tornar visíveis estas estratégias, são elas: estrutura dos conteúdos, imagem territorial e distribuição cromática dos tipos raciais.

Nossa analise recai sobre três coleções destinadas ao segundo segmento do ensino fundamental: Espaço e Vivência, da Editora Saraiva; Para Viver Juntos: Geografia, da edições SM e a Coleção Araribá, da Editora Moderna. Os critérios determinantes para a escolha das coleções foram: primeiro a aprovação de todas elas no Programa Nacional do Livro Didático 2011 (PNLD 2011) e o segundo foi a ampla utilização desses compêndio nas escolas das redes públicas.

\section{Análise da Estrutura}

O universalismo europeu também contaminou a produção de saberes nos espaços subalternos, que estruturam seu próprio pensamento segundo uma lógica que tende a favorecer os antigos (?) colonizadores. Esta epistemologia hegemônica trabalha com polarizações, extremos opostos que tornam severas as representações que se tem do outro e de tudo aquilo que não é europeu. Essas polarizações são hierarquizantes e tem como ponto de chegada a idéia do que seja a civilização européia. Tal estrutura funciona em uníssono com a idéia de evolução. Como se todos os povos saíssem de um estado comum - estado de natureza - e estivessem a caminho do ápice, que seria o modelo de civilização protagonizado pela sociedade européia. É a evolução da técnica e da tecnologia que permitiria esse trânsito de um pólo ao outro. Essa construção tem por base uma "visão de mundo que aponta a Europa como superior aos outros continentes" (Santos, in. Souza, 2009, p.112). Nesse sentido opera o que Boaventura de Souza Santos chama de "monocultura do tempo linear", que é "uma forma de ler o mundo segundo a qual 'a história tem sentido e direção únicos', sempre rumo a um futuro que é concebido como progresso, desenvolvimento, revolução, modernização, 


\section{REVISTA TAMOIOS}

crescimento(...)" (ibid, p.114). Segundo essa lógica onde raça-cultura-espaçotempo operam juntos, as diferenças técnicas e culturais são concebidas como assimetrias temporais; um grupo ou espaço passa a ser mais "avançado" que o outro por conta de sua relação com a tecnologia; outros ficaram no passado, por conta das técnicas rudimentares que aplicam no presente, ou por conta de uma cultura mais ligada e dependente da natureza. Assim, simultaneidades são transformadas em sucessividades, e o quê ou quem se apresenta com maior domínio das técnicas e tecnologias está passos à frente dos demais.

É neste contexto que "subdesenvolvimento" deixa de ser somente uma classificação econômica e social e para representar uma assimetria temporal em relação aos espaços "desenvolvidos", o mesmo ocorre quando se estabelece a oposição entre o "rural" e o "urbano".

Além disso, as coleções apresentam uma nítida separação entre "natureza" e "homem" - uma fissura, portanto entre "Geografia Física" e "Geografia Humana". Os espaços - independente da escala - são apresentados a partir dos seus aspectos naturais em seguida, seus aspectos "humanos". A oposição cartesiana entre razão e natureza, se faz presente nos livros didáticos através dos seus correspondentes: paisagem natural e humanizada; Rural e urbano; Subdesenvolvimento e desenvolvimento.

\section{Imagem Territorial (apresentação dos continentes)}

Interessa-nos aqui verificar a lógica de apresentação dos continentes e a maneira com que os livros didáticos analisados desenvolvem uma representação negativa dos países não-europeus e a forma como que a estrutura baseada no dualismo-evolucionismo, que é marca do pensamento europeu universalizado, aparece associado a produção/reprodução das identidades geoculturais, contribuindo para a hierarquização de espaços e grupos humanos. Considerando a distribuição dos conteúdos a ênfase desta chave analítica recai sobre os livros do oitavo e nono ano.

Os livros de oitavo e nono ano se complementam no que tange ao dualismo, o primeiro enfatiza em seus conteúdos estudos sobre 0 subdesenvolvimento, as características econômicas, políticas e sociais e, inclusive, a aparência física de seus elementos humanos. Daí o elevado número de imagens de pretos e pardos nos livros do oitavo ano/ sétima série, em comparação com os outros exemplares dos compêndios', pois são nos exemplares de oitavo ano que a África é selecionada como conteúdoii, ou ainda, como já antes dito, o subdesenvolvimento é enfatizado. Desta forma a relação entre as imagens evidenciando pretos e pardos, o espaço e o nível de "(sub)desenvolvimento" é reforçado. A imagem de África, dos africanos e dos afrodescendentes é vinculada ao setor primário da economia, as formas tradicionais de relação com a natureza e trabalho, fome e pobreza.

As limitações técnicas - segundo o padrão universalizado - são visíveis nas imagens dos conteúdos que abordam os territórios "subdesenvolvidos", seja na construção da maioria dos imóveis ou mesmo na organização dos espaços (aglomerações caóticas, favelização e outros). Os problemas referentes à África, Ásia e América Latina, são abordados de maneira enfática, e apresentados como prioritariamente de ordem econômica, a solução que se esboça parece residir no "desenvolvimento", no desenvolvimento econômico.

A incapacidade de gerir suas economias de modo satisfatório a fim de escapar das amarras do atraso e dos problemas de não ser "desenvolvido", 
sugere como solução o auxílio externo, daí uma série de acordos com organismos internacionais - que reforçam a dependência dos países pobres em relação aos ricos - e a entrada das multinacionais. Se antes os povos africanos, asiáticos e ameríndios resistiam as invasões estrangeiras como forma de resguardar seu espaço, hoje, o antigo colonizador (?) é convidado e tem sua entrada facilitada por governos que oferecem, além da isenção fiscal, terrenos (espaços) para terem sua mão-de-obra explorada ao extremo. As portas se abrem, o discurso do desenvolvimento - e suas benesses - torna legítima a invasão e o sonho do desenvolvimento parece chegar nos braços das multinacionais.

Ao contrário do que acontece com disposição das imagens no conteúdo sobre África, no que se refere a "América", o homem americano pouco é retratado de forma bem visível. No entanto, nas três imagens mais nítidas na coleção Geografia: Espaço e Vivência, os homens e as mulheres são declarados - na legenda da ilustração - ou apresentam fortes traços indígenas; somado a isso, figuras desenhadas em rocha, objetos e esculturas de antigos povos ameríndios, fazem uma forte alusão a identidade geocultural que predomina na representação do livro didático de Geografia referente aos latinoamericanos: são indígenas. Na coleção Para Viver Juntos: Geografia, gravuras de indígenas e negros adornam o exemplar no conteúdo referente a América Latina, nos capítulos que tratam da América Anglo-Saxônica predominam imagens representando somente pessoas de cor branca. Tanto negros, quanto indígenas, de acordo com o pensamento moderno, são uma resistência de um tempo que não existe mais, são "passado". As imagens de do livro didático nos lembra disso, ao apresentar gravuras e pinturas referentes ao trabalho escravo no período colonial e nenhuma ou poucas imagens representando uma inserção digna de negros e indígenas atualmente no mercado de trabalho.

No livro didático, o atraso é a marca do continente africano e da América Latina. A incapacidade de gerir seus problemas de modo satisfatório parece apontar para a necessidade de ajuda. Assim como Ginés de Sepúlveda acreditava que a intervenção espanhola na América era uma necessidade para salvar os ameríndios de suas práticas desumanas - logo, de si mesmos -, diante do argumento da necessidade urgente de uma ação externa para neutralizar as calamidades que assolam os espaços mais pobres do planeta a resistência se afrouxa. A estrutura do discurso presente no livro didático e a forma como ele é conduzido põe em xeque a crença na capacidade de autogestão dos países americanos e africanos, reforçam a posição de dependência e, pior, a apresentam como uma necessidade para superação da própria dependência.

No que diz respeito a Ásia, o discurso é outro. Afinal, como diz Wallerstein no século XIX os europeus chamavam as populações dessa região de "civilizações avançadas", "conceito que incluía, entre outros, a China, Índia, Pérsia e Império Otomano" (2007, p.64), portanto, a representação universal européia - de Ásia, é aquela que irá predominar nos livros didáticos de Geografia do ensino fundamental.

O Oriente Médio é apresentado como uma região de conflitos, onde a religião é o elemento cultural de unificação e discórdia. Região que tem no petróleo seu principal recurso e fator de instabilidade política nos países produtores não alinhados as potências hegemônicas. 


\section{REVISTA TAMOIOS}

As imagens de Ásia contrabalançam miséria e opulência. O Oriente é contraditório nessa versão, é um meio termo entre África, América Latina e Europa.

Os livros do nono ano dedicam maior parte dos conteúdos a discussão dos espaços desenvolvidos. Percebemos que, em média, em sessenta por

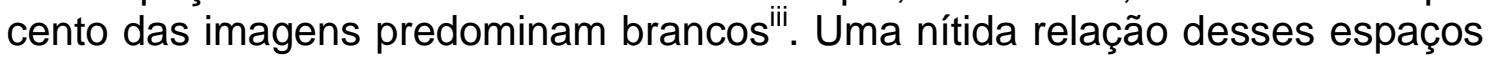
com uma raça e povo específico, os europeus.

Os poucos negros que aparecem no conteúdo referente ao estudo da Europa, são representados ilustrando os textos que tratam de tráfico internacional de trabalhadores, relacionando as imagens dos imigrantes africanos à clandestinidade, a ilegalidade.

Quando o assunto é América do Norte - e o mesmo se dá com o continente europeu -, a discussão sobre o setor primário é curta e relacionada a produção industrial. Aliás, um confronto entre os títulos e subtítulos de ambos exemplares (oitavo e nono ano) permite perceber o descompasso, ou a oposição, na representação de espaço que o livro didático se propõe a reproduzir e transmitir. Só para citar alguns exemplos retirados dos índices: As multinacionais na economia latino-americana - a expansão das multinacionais e do comércio norte-americano; o endividamento externo da América-Latina - a influência dos Estados Unidos na economia, cultura e na geopolítica mundial; África dos grandes fluxos migratórios - Os imigrantes na Europa desenvolvida; Estados Unidos: Superpotência Mundial - Raízes do Subdesenvolvimento Africano; Investimento Estrangeiro e Desenvolvimento Econômico (na África).

Nos Estados Unidos, assim como na Europa o principal problema são os imigrantes. A imigração é apresentada como um problema provocado "pelos outros". Assim, a intervenção deve ser feita nos países de emigração - apesar do desrespeito aos direitos humanos, critério para intervenção estrangeira, ocorrer no espaço que recebe estes imigrantes -; sendo assim este é um problema cuja origem, sugere, está na incapacidade das economias subdesenvolvidas em se estruturar de forma a absorver esse quantitativo de trabalhadores que migram, ou frear de alguma forma o fluxo migratório e não na desestruturação social, política e econômica provocada pelos europeus nos espaços coloniais e a manutenção de relações injustas entre os países europeus e os demais países do mundo que torna inviável para muitos a possibilidade de ascensão social em seu próprio país.

Não há uma gênese, um processo de formação do continente europeu, enquanto os outros continentes, principalmente os que concentram estados "subdesenvolvidos" são estudados a partir do contato com os europeus, se constroem a partir de então, a Europa aparece sem explicação, sem história, "naturalmente". Um ente autônomo que supostamente não necessitou de outras áreas para se constituir. Esta representação apaga o papel da América e da África como protagonistas (por que não?) do crescimento econômico europeu, pois sem os braços (e o sangue!) africanos e indígenas e os metais preciosos da América, seria impossível e impensável as conquistas territoriais das nações européias para além do continente.

\section{Distribuição das Categorias Cromáticas}

Essa parte da análise consiste em duas etapas: na primeira, que classificamos como análise quantitativa, buscamos observar quantas imagens aparecem nos exemplares das três coleções de livros didáticos de Geografia selecionadas representando os diferentes tipos raciais; e na segunda, fizemos 


\section{REVISTA TAMOIOS}

a análise qualitativa destas imagens, onde discutimos seu contexto, ou seja, as condições em que os tipos humanos são representados.

A ação de classificar os sujeitos representados nos livros, levando-se em consideração a relação entre grupos raciais e categorias cromáticas (branco, preto, amarelo, por exemplo), mostra-se bastante complexa. Algo que no cotidiano se mostra tão flutuante nos livros didáticos é também motivo de intensas reflexões.

Levando-se em consideração que a classificação racial de um indivíduo se faz a partir de um somatório de condicionantes e que o próprio conceito de raça se fez como constructo socialmente produzido, convencionamos que a classificação das pessoas representadas nas obras seguiria o padrão utilizado pelo Instituto Brasileiro de Geografia e Estatística que define desta forma: Pretos, Pardos, Indígenas, Amarelos e Brancos.

Após definirmos as características cromáticas, outras questões vieram à tona. A primeira é que algumas figuras aparecem em preto e branco e em outras a distância e a iluminação prejudica a identificação cromática das pessoas ou da pessoa presente nas imagens - neste caso, as classificamos como sendo de "Difícil Identificação".

O segundo questionamento foi que em algumas imagens apresentadas pelos livros percebemos a presença de pessoas de características cromáticas diferentes, brancos e negros dividindo a mesma figura. Neste caso criamos outra categoria analítica que é a "Imagem Compartilhada". Outro aspecto metodológico importante é destacar que analisamos somente figuras representando pessoas. O processo classificatório complexifica-se quando começam as tentativas de definição das categorias intermediárias, ou seja, qual a fronteira que separa o preto e o pardo? Essa confusão se torna presente porque os campos da classificação racial não operam sozinhos. E é justamente essa operação em conjunto que tornará fluida essa classificação. Essa fluidez classificatória será caracterizada também pelos diferentes posicionamentos dos pesquisadores, inclusive. Uma hora o indivíduo pode ser classificado como preto, dependendo da situação em que ele se encontre na imagem, ou pode ser visto como pardo, ou qualquer outra classificação. No entanto, a partir de várias negociações, chegamos a seguinte distribuição cromática:

\section{Tabela 1}

\begin{tabular}{|c|c|c|c|c|c|}
\hline \multicolumn{6}{|c|}{ 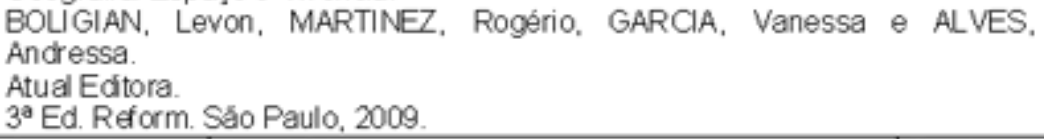 } \\
\hline \multirow{2}{*}{$\begin{array}{l}\text { Categoria } \\
\text { Cromética }\end{array}$} & \multicolumn{4}{|l|}{ Ano / Série } & \multirow{2}{*}{$\begin{array}{l}\text { Total } \\
\text { (Coleçáo) }\end{array}$} \\
\hline & $\begin{array}{l}6^{\circ} \text { ano/5 } \\
\text { série }\end{array}$ & $\begin{array}{l}7^{\circ} \text { ano } / 6^{\circ} \\
\text { série }\end{array}$ & $\begin{array}{l}8^{\circ} \text { ano } / 7^{\circ} \\
\text { série }\end{array}$ & $\begin{array}{l}g^{\circ} \text { andors } \\
\text { série }\end{array}$ & \\
\hline Preto & 2 & 3 & 22 & 3 & 30 \\
\hline Pardo & 4 & 7 & 4 & 1 & 16 \\
\hline Branco & 61 & 27 & 37 & 51 & 176 \\
\hline Amarelo & 0 & 2 & 9 & 10 & 21 \\
\hline Indigena & 1 & 4 & 4 & 1 & 10 \\
\hline $\begin{array}{l}\text { Difidil } \\
\text { identificação }\end{array}$ & 7 & 12 & 5 & 10 & 34 \\
\hline $\begin{array}{l}\text { Imagem } \\
\text { Compartilhada }\end{array}$ & 3 & 7 & 13 & 6 & 29 \\
\hline Total & 78 & 62 & 94 & 82 & 316 \\
\hline
\end{tabular}




\section{REVISTA TAMOIOS}

\section{Tabela 2}

\begin{tabular}{|c|c|c|c|c|c|}
\hline \multicolumn{6}{|c|}{$\begin{array}{l}\text { Para VWer Juntos Geografia. } \\
\text { Sampaio, Fernando dos Santos } \\
\text { Ediçôes SM. } \\
1 \text { ed. Ver., Sâo Paulo, } 2009 .\end{array}$} \\
\hline \multirow{2}{*}{$\begin{array}{l}\text { Categoria } \\
\text { Cromática }\end{array}$} & \multicolumn{4}{|c|}{\begin{tabular}{|l|} 
Ano / Série \\
\end{tabular}} & \multirow{2}{*}{$\begin{array}{l}\text { Total } \\
\text { (Co leçăo) }\end{array}$} \\
\hline & $\begin{array}{l}6^{\circ} \\
\text { anol } 5^{2} \\
\text { série }\end{array}$ & $\begin{array}{l}7^{\circ} \text { ano/ } \sigma^{\circ} \\
\text { série }\end{array}$ & $\begin{array}{l}8^{\circ} \text { and }^{\text {an }} 7^{2} \\
\text { série }\end{array}$ & $\begin{array}{l}9^{\circ} \text { an } \alpha \delta^{\circ} \\
\text { æérie }\end{array}$ & \\
\hline Preto & 1 & 2 & 14 & 1 & 18 \\
\hline Pardo & 2 & 4 & 4 & 6 & 16 \\
\hline Branco & 43 & 46 & 18 & 39 & 146 \\
\hline A.marelo & 3 & 3 & 5 & 0 & 11 \\
\hline Indigena & 1 & 1 & 3 & 17 & 22 \\
\hline $\begin{array}{l}\text { Imagem } \\
\text { Compartilhada }\end{array}$ & 1 & 17 & 19 & 8 & 45 \\
\hline $\begin{array}{l}\text { Difícil } \\
\text { identificação }\end{array}$ & 10 & 22 & 7 & 2 & 41 \\
\hline Total & 61 & 95 & 70 & 73 & 299 \\
\hline
\end{tabular}

\section{Tabela 3}

\begin{tabular}{|c|c|c|c|c|c|}
\hline \multicolumn{6}{|c|}{$\begin{array}{l}\text { Projeto Araribá: Geografia } \\
\text { Obra Coletiva, desenvolvida e produzida pela Editora Moderna } \\
\text { Editora Moderna } \\
\text { 2.ed, Sâo Paulo, } 2007 \text {. }\end{array}$} \\
\hline \multirow{2}{*}{$\begin{array}{l}\text { Categoria } \\
\text { Cromática }\end{array}$} & \multicolumn{4}{|l|}{ Ano / Série } & \multirow{2}{*}{$\begin{array}{l}\text { Total } \\
\text { (Coleçâ) }\end{array}$} \\
\hline & $\begin{array}{l}6^{\circ} \text { ano/5 } \\
\text { série }\end{array}$ & $\begin{array}{l}7^{\circ} \text { ano/6 } \\
\text { série }\end{array}$ & $\begin{array}{l}8^{\circ} \text { ano/7 } \\
\text { série }\end{array}$ & $\begin{array}{l}g^{\circ} \text { and } / 8^{3} \\
\text { série }\end{array}$ & \\
\hline Preto & 5 & 5 & 10 & 20 & 40 \\
\hline Pardo & 4 & 3 & 2 & 12 & 21 \\
\hline Branco & 58 & 51 & 63 & 103 & \begin{tabular}{|l|}
275 \\
\end{tabular} \\
\hline Amarelo & 3 & 0 & 2 & 8 & 13 \\
\hline \begin{tabular}{|l} 
Indigena \\
\end{tabular} & 2 & 4 & 8 & 0 & 14 \\
\hline $\begin{array}{l}\text { Difídil } \\
\text { identificação }\end{array}$ & 13 & 9 & 15 & 12 & 49 \\
\hline $\begin{array}{l}\text { Imagem } \\
\text { Compartilh ada }\end{array}$ & 5 & 17 & 4 & 4 & 30 \\
\hline Total & 90 & 89 & 104 & 159 & 442 \\
\hline
\end{tabular}

O que existe de comum em todos os exemplares de todas as coleções é o predomínio absoluto de um tipo racial específico, o branco. Em termos cromáticos o mundo é extremamente heterogêneo, neste caso, conclui-se que o livro didático não representa o mundo em sua complexidade, representa sim, uma visão deturpada e provinciana do mundo com base num modelo eurocentrado e extremamente limitado.

O predomínio do padrão cromático não-branco é evidente inclusive quando os livros se dedicam aos estudos da Geografia do Brasil (sétimo ano/sexta série) ou quando enfatizam o mundo subdesenvolvido. Nos livros destinado ao sétimo ano/ sexta série, acreditamos que há uma tentativa de forjar um tipo racial pátrio. Mas em todos os casos, o que se percebe é a exclusão do "outro", não condizente com o padrão - europeu, logo, local, porém universalizado - em voga.

A diferença entre o protagonista e o coadjuvante está dentre outras coisas no papel de um e de outro no enredo da história, que é contada a partir de um ponto de vista e quem ousa contar a história não atribui a si um papel secundário. Interessa-nos outras histórias, outros pontos de vista. O material didático analisado exalta um tipo cromático em detrimento dos demais, promove invisibilizações ou não-existências. Já dizia Boaventura de Souza Santos que "muito do que não existe em nossa realidade é produzido ativamente como não-existente" (2007, p.28), logo, ao nosso ver, não há 


\section{REVISTA TAMOIOS}

coincidência e muito menos imparcialidade na seleção das imagens e na distribuição quantitativa dos tipos cromáticos.

Ao conjugarmos o resultado da análise quantitativa com a forma como os não-brancos são apresentados nas imagens dos livros didáticos, podemos perceber nitidamente um processo de inferiorização de tipos raciais, uma vez que: i) crianças pretas e pardas são expostas em situações degradantes; ii) pretos, pardos e indígenas aparecem executando tarefas de baixa qualificação. O que não signifique que não apresenta brancos em funções similares, a diferença é que o livro retrata estes últimos como profissionais especializados também, o que não ocorre com indígenas, pretos e pardos. Os brancos estão presentes em todas as esferas do trabalho, os não-brancos originais da América e África, somente nas inferiores. Além disso, esses grupos são representados utilizando técnicas tradicionais de produção, o que sugere improdutividade. Também encontramos nos exemplares imagens de escravos tanto negros quanto indígenas e a relação entre essas imagens e as formas de trabalho em que os esses grupos raciais executam, segundo o que se vê nos livros didáticos, sugere uma anacronia, ou seja, eles figuram como residuais, incapazes de acompanhar as evoluções tecnológicas, cristalizaram-se no passado. A epistemologia européia converte as diferenças culturais e técnicas em assimetrias temporais; iii) as imagens de pretos e pardos aparecem com mais freqüência nos conteúdos referentes a África, a miséria, a ilegalidade e a outros fatores negativos; iv) há uma naturalização das diferenças, uma vez que as condições histórico-estruturais que lançaram determinadas categorias raciais em uma situação desfavorável não são explicitadas. Induz a crença de que a condição social é conseqüência de uma incapacidade nata de determinados grupos raciais; v) ocorre um alisamento espacial, pois pouco ou nada se fala sobre os espaços de maioria negra presentes nas zonas rurais e urbanas.

\section{Conclusão}

Tomando pelo todo, os livros didáticos de Geografia do Ensino Fundamental estabelecem uma sinonímia para os termos utilizados no século $\mathrm{XVI}$ e XIX que serviam de justificativa moral para qualificar como inferiores os povos dos continentes conquistados, essa inferioridade se construía segundo critérios raciais e culturais. A produção dessa inferioridade servia como base para construção de argumentos morais que justificavam e que atribuíam ao europeu o "direito a ingerência".

Seria uma grosseria utilizar na relação entre povos no mundo contemporâneo termos como "civilizados" e "bárbaros"; no entanto, eufemismos cabem. No imaginário europeu parece que os não-europeus caminharam muito pouco na tentativa de sair desse enquadramento. Ser definido como "subdesenvolvido" parece uma alusão a antiga terminologia aplicada a indígenas e africanos bárbaros.

Da mesma maneira que "No século XIX, as potências européias proclamaram que tinham uma missão civilizadora no mundo colonial" (Wallerstein, 2007, p.40), as nações "desenvolvidas" do século XXI atribuem a si um papel moral de interferir no espaço mundial - entenda subdesenvolvidos - sempre que a democracia e os direitos humanos forem ameaçados. $\mathrm{Na}$ verdade, não é isso que está em jogo. Conforme apresentamos em linhas anteriores, o alvo é o espaço, controle de recurso, o discurso sobre valores 


\section{REVISTA TAMOIOS}

operam como uma cortina de fumaça que impede a opinião pública de enxergar as verdadeiras razões das intervenções.

Nossa inquietação está em perceber que o material didático que tem como um dos fins apresentar o mundo ao educando, foi construído com base na epistemologia do pensamento europeu. Com isso a representação de mundo difundida nos exemplares desta coleção prima a hierarquização de espaço e de grupos humanos, enfatiza as carências dos países conceituados como subdesenvolvidos e exalta os desenvolvidos atribuindo a eles mesmos o mérito de sozinhos ascender a posição que hoje ocupam no sistema-mundo-modernocolonial. De modo silencioso atribui uma "cor" para cada continente, reforçando as identidades geoculturais. Espaços inferiorizados são habitados por gente considerada inferiorizada, cuja "cor" é o estigma dessa inferioridade sócioespacial.

Quando argumentos morais dos países desenvolvidos justificarem intervenções nos países subdesenvolvidos - cujos motivos principais quase sempre se escoram na espoliação de povos cujo pertencimento racial difere dos europeus - e o direito a soberania destes for desconsiderada, a escola terá sido a primeira instituição a legitimar o ato.

\section{Notas}

I - Nos exemplares que trazem África em seu conteúdo, a distribuição cromática se dá na seguinte proporção: Geografia: Espaço e Vivência, 22 pretos e 4 pardos contra 37 brancos, número elevado de pretos e pardos se comparados aos outros exemplares da mesma coleção, onde a exposição de imagens dessa categoria cromática não chega a 15\% desta quantidade. No Para Viver Juntos: Geografia, são 14 pretos e 4 pardos contra 18 brancos. Considerando que em todos os outros exemplares o número de pretos e pardos somados chega a 16. Nota-se uma elevada concentração de negros num só exemplar.Na coleção Araribá, a quantidade de imagens mostrando exclusivamente pretos ou pardos ficam restritas a 32 contra 103 brancos, cabe expor que "África" é conteúdo do livro de nono ano/oitava série nesta coleção, onde a ênfase é dada aos conteúdos referentes a "Europa" (duas unidades, enquanto que os outros continentes contam com apenas uma).

II - Com exceção da coleção Araribá, que trabalha África no livro do nono ano.

III - Espaço e Vivência, 62\% de imagens representando brancos; Para Viver Juntos: Geografia, 53\% de imagens de branco e Coleção Araribá, 65.

\section{Referências Bibliográficas}

Boligian, Levon, Martinez, Rogério, Garcia, Wanessa e Alves, Andressa.Geografia Espaço e Vivência: Introdução à Ciência Geográfica, 3aㅡ ed. reform., obra em 4 v. para alunos do 6ํㅜ ao 9aㅡ. São Paulo: Atual, 2009. 
Cavalcanti, Lana de S. Geografia, Escola e Construção de Conhecimento. Campinas, Papirus Ed., 1988.

Costa, Raphael Luiz Silva da. Racismo e livros didáticos de Geografia: A Lei 10639 como instrumento de descolonização do conhecimento e por uma nova racionalidade. São Gonçalo: FFP/UERJ, Monografia apresentada no curso de graduação de Licenciatura em Geografia

Guia de Livros Didáticos: PNLD 2011: Geografia. - Brasília: Ministério da Educação, Secretaria de Educação Básica, 2010.

Projeto Araribá: Geografia: Ensino Fundamental/Obra Coletiva Concebida, Desenvolvida e Produzida pela Editora Moderna, $2^{\underline{a}}$ ed., obra em 4 v. para alunos de 6ำ ao 9ำ ano. São Paulo: Moderna, 2007.

Sampaio, Fernando dos Santos. Para Viver Juntos: Geografia, $1^{\underline{a}}$ ed. rev., obra em 4v. para alunos de 6ำ ao 9ำ ano. São Paulo: Edições SM, 2009.

Santos, Boaventura de Souza. Renovar a Teoria Crítica e Reinventar a Emancipação Social. São Paulo: Boitempo, 2007.

Santos, Cesar Augusto Caldas dos. Novas Manifestações de Racismo no Livro Didático de Geografia do Ensino Fundamental. São Gonçalo: FFP/UERJ, Monografia apresentada ao curso de pós-graduação latu sensu em Ensino de Geografia. 2008.

Santos, Renato Emerson dos (org.). Diversidade, Espaço e Relações Sociais: O Negro na Geografia do Brasil. Belo Horizonte: Autêntica, 2007.

O Ensino de Geografia e os Tensionamenteos da Lei 10.639: Nótulas para um Debate em Construção. In.: Souza, Maria Elena Viana (org.). Relações Raciais no Cotidiano Escolar: Diálogos com a Lei 10.639/03. Rio de Janeiro: Rovele, 2009.

Wallerstein, Immanuel. O Universalismo Europeu. A Retórica do Poder. São Paulo: Boitempo, 2007. 